\title{
DELAYED ARTERIAL OCCLUSION IN LIMB INJURIES
}

\author{
Report of Three Cases
}

\author{
M. F. Porter, Birmingham, England \\ From the Birmingham Accident Hospital
}

Major arterial occlusion is an uncommon complication of limb injury, occurring in a recent series in about one case in 1,100 admitted to an accident unit (Porter 1967). When the occlusion occurs at the time of injury diagnosis is fairly straightforward, but when it occurs later diagnosis may be more difficult and is liable to be delayed.

Delayed occlusion after orthopaedic manipulation or operation was described by Stein (1956) and by Roper and Provan (1965). Delayed occlusion occurring as a result of the initial injury and without the possibility of any further damage having taken place appears to have received less attention. Three cases in which this happened are described.

\section{CASE REPORTS}

Case 1-A forty-two year old man, pushing a car, was run into from behind and crushed between the bumpers. At admission thirty minutes later he was found to have a compound supracondylar fracture of the right femur, with a transverse wound in the popliteal fossa, fractures of the head and shaft of the fibula (Fig. 1), and a compound dislocation of the

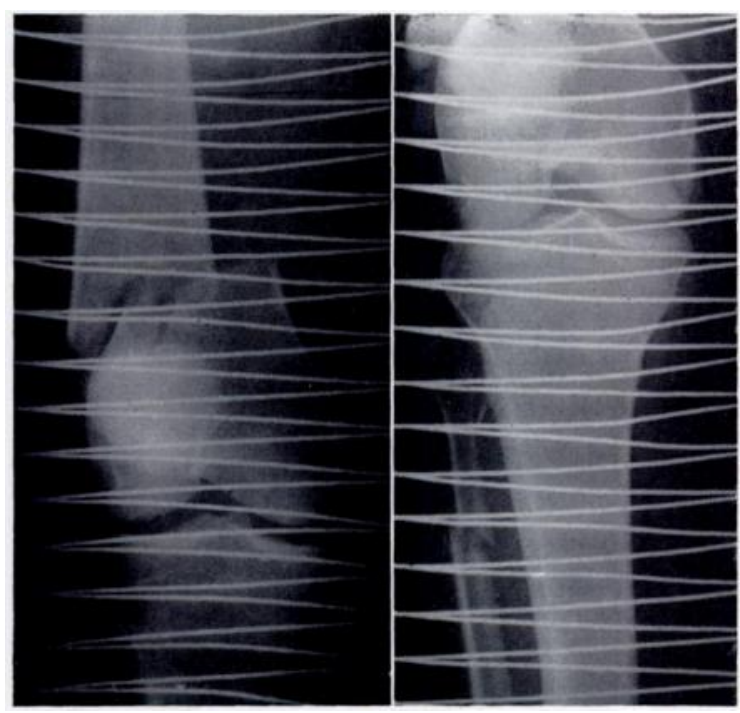

Fig. 1

Case 1-The supracondylar fracture of the femur, and fractures of head and shaft of the fibula, on admission. same ankle. At operation two and threequarter hours after injury, the femur was fixed with a blade-plate. The popliteal artery was seen to be contused, but it was patent and pulsating normally distal to the contusion. The dorsalis pedis pulse was present at the end of the operation. The limb was rested in a Thomas's splint, with careful avoidance of pressure at knee level. At no time was there swelling or pain sufficient to suggest compression in a closed compartment (Nolan and McQuillan 1965), but the leg slowly showed signs of ischaemia, and the dorsalis pedis pulse was unequivocally absent on the fourth day. When below-knee amputation was performed on the eighth day, ischaemic necrosis of muscle was apparent to four inches below the knee in all muscle groups.

Case 2-A forty-nine year old man was injured in the same accident and in the same fashion as the patient in Case 1. He sustained a severe compound fracture of the midshaft of the left tibia and fibula, and bruising, abrasions and a shallow cut over the front of the right knee, but without bony injury in this leg. Operation was started four hours after injury and consisted in intramedullary nailing of the left tibia with closure of the wound by suture and skin graft. The right knee wound was sutured. At the end of the operation normal pulses were present in both feet. Thirteen hours after injury the right foot was found to be colder than the left, with absent pulses. Cooling, intravenous heparin and low-molecular 
weight dextran were given, but without benefit. Twenty-one hours after the injury the right popliteal artery was explored and found to be contused, with an intimal tear and thrombosis. End-to-end anastomosis was done after resection of the injured segment with immediate restoration of colour and warmth, but not pulses, to the foot. Two days later marked swelling of the leg below the knee became apparent. There was ultimately evidence of muscle ischaemia in the form of wasting and some contracture of the right calf.

Case 3-A forty-four year old man fell from his bicycle sustaining a closed comminuted fracture of the lower end of the right femur (Fig. 2). Upon his admission twenty minutes

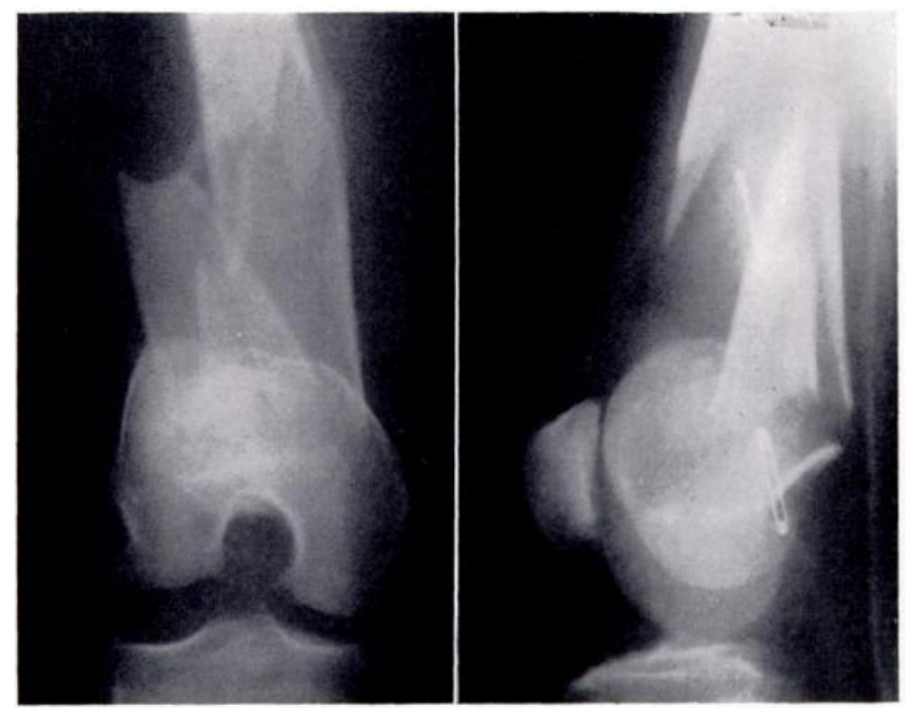

FIG. 2

Case 3-The comminuted supracondylar fracture of the femur.

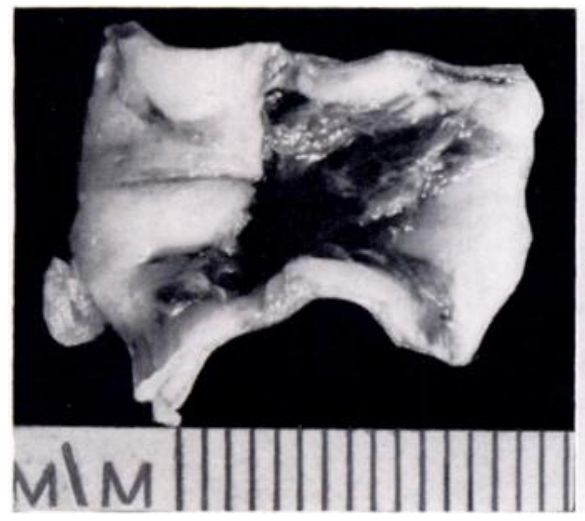

Fici 3

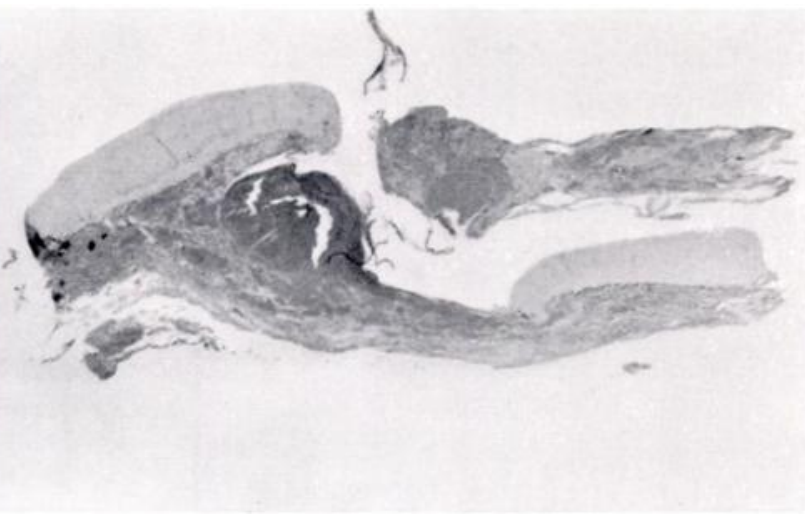

FiG. 4

Case 3. Figure 3-The excised segment of the popliteal artery, showing the intimal tear and thrombus. The proximal end is on the right. Figure 4-Photomicrograph of the vessel wall, showing the thrombus; its detachment is an artefact. The proximal end of the artery is to the right, and the lumen faces upwards. (Haematoxylin and eosin, 5).

later blood transfusion was started, a Steinmann pin was inserted through the upper tibia, and a Thomas's splint was applied. At that time normal pulses were present in the right foot. Five hours after the injury he complained of much pain in the calf and numbness of the foot, which was found to be colder than the left and with absent pulses. On exploration of the popliteal artery six and a half hours after injury, a contusion was obvious externally, 
with tearing of the intima and thrombosis (Figs. 3 and 4). End-to-end suture after resection of one and a half inches immediately restored normal circulation and pulses to the foot. The fracture was fixed with Rush pins.

\section{DISCUSSION}

Contusion of the wall of an artery with varying degrees of disruption of its coats was described by Sencert (1918). The damage may vary from minute cracks in the intima to complete circumferential rupture of intima and media. In the latter case marked retraction of the severed coats causes immediate occlusion, and a similar result may follow from tearing of the intima alone, if it is accompanied by much dissection. If intimal damage is less, retraction may be relatively small and insufficient to block the lumen. Thrombus may then be deposited on the exposed and partly damaged media, slowly building up to complete occlusion some hours later. By this time primary treatment may have been completed and vigilance somewhat relaxed. Earlier observation of patency of the vessel, as in Case 1, may also be misleading.

It is now generally accepted that all patients with limb ischaemia following injury should be subjected to exploration after only the briefest of delays with conservative treatment. These cases demonstrate that the initial presence of good circulation should in no way alter this policy if subsequent deterioration occurs. In addition, it is suggested that any limb artery seen to be contused but patent in the course of wound exploration should be opened, lest it be the site of an ultimately occlusive lesion in its early stages.

In treatment, both resection of the affected segment and thrombo-endarterectomy have been recommended and performed on a number of occasions (Bonney 1963; Beall, Diethrich, Morris and De Bakey 1966). While the latter method may usefully avoid the need for a graft and be perfectly satisfactory when damage to the vessel wall does not extend deeply, it may be hazardous when damage to the media is other than minimal. In civilian practice in this country the occasions when a graft is in fact needed to bridge a defect are very few.

\section{SUMMARY}

1. Three cases of delayed occlusion of the popliteal artery following trauma are described.

2. The lesion responsible is a partial rupture of the vessel with subsequent thrombosis.

3. All such lesions should be explored and preferably resected.

It is a pleasure to record my thanks to Dr S. Sevitt for the photomicrograph, and to $\mathrm{Mr} \mathbf{N}$. R. Gill for the radiographic reproductions.

\section{REFERENCES}

Beall, A. C., Diethrich, E. B., Morris, G. C., and De Bakey, M. A. (1966): Surgical Management of Vascular Trauma. Surgical Clinics of North America, 46, 1001.

BonNey, G. (1963): Thrombosis of the Femoral Artery Complicating Fracture of the Femur. Journal of Bone and Joint Surgery, 45-B, 344.

Nolan, B., and McQuillan, W. M. (1965): Acute Traumatic Limb Ischaemia. British Journal of Surgery, 52, 559.

PORTER, M. F. (1967): Arterial Injuries in an Accident Unit. British Journal of Surgery, 54, 100.

Roper, B. A., and Provan, J. L. (1965): Late Thrombosis of the Femoral Artery Complicating Fracture of the Femur. Journal of Bone and Joint Surgery, 47-B, 510.

SENCERT, L. (1918): Wounds of the Vessels. London: University of London Press Ltd.

Stein, A. H. Jr. (1956): Arterial Injury in Orthopaedic Surgery. Journal of Bone and Joint Surgery, 38-A, 669. 